\title{
A RUPTURA NA QUÍMICA ENTRE O SENSO COMUM E O CONHECIMENTO CIENTÍFICO A PARTIR DA ANÁLISE DE GASTON BACHELARD
}

\author{
David Velanes ${ }^{1}$ \\ Universidade Federal de Minas Gerais (UFMG) \\ iD https://orcid.org/0000-0002-8992-6701
}

\begin{abstract}
RESUMO:
O objetivo deste artigo é demonstrar a ruptura entre senso comum e conhecimento científico da Química a partir da epistemologia de Gaston Bachelard. Como fio condutor para tal análise, tomou-se os conceitos de materialismo imediato e materialismo instruído, que aparecem principalmente na obra bachelardiana Le Matérialisme Rationnel de 1953, como grandes bases de pensamentos que fundamentaram a ciência Química em períodos históricos diferentes. Demonstrar-se-á que, na epistemologia de Bachelard, o conceito de materialismo imediato equivale ao momento em que ocorria continuidade entre senso comum e conhecimento científico e que as diversas rupturas e inovações conceituais que ocorreram na contemporaneidade irão instaurar uma nova Química, fundamentada em uma nova base de pensamento, intitulada por Bachelard de materialismo instruído. Aqui, o materialismo se encontra no estado avançado da cultura científica e, ao incorporar o conhecimento discursivo sobre a matéria, rompe com os conhecimentos das aparências e se distancia definitivamente das ideias elementares ligadas ao senso comum. A Química do novo espírito científico é apresentada pela epistemologia bachelardiana como uma ciência inventiva que cria seu objeto, ela instruí e ordena a realidade a partir do pensamento matemático através de técnicas muito peculiares e, deste modo, se distancia da análise imediata sobre os dados empíricos da realidade comum. A epistemologia da química bachelardiana aponta para uma série de reorganizações e atualizações conceituais que servem para caracterizar as provas da evolução do pensamento científico.
\end{abstract}

PALAVRAS-CHAVE: Bachelard; Materialismo; Química; Senso comum; Ruptura.

${ }^{1}$ Doutorando na linha de pesquisa em Lógica, Ciência, Mente e Linguagem do Programa de Pós-Graduação em Filosofia da Universidade Federal de Minas Gerais (UFMG), Minas Gerais - Brasil. E-mail: dvelanes@gmail.com

A ruptura na química entre o senso comum e o conhecimento científico a partir da análise de Gaston Bachelard David Velanes

Griot : Revista de Filosofia, Amargosa, Bahia - Brasil, v.15, n.1, p.187-203, junho/2017 


\title{
THE RUPTURE IN CHEMISTRY BETWEEN COMMON SENSE AND SCIENTIFIC KNOWLEDGE FROM THE ANALISIS OF GASTON BACHELARD
}

\begin{abstract}
:
The aim of this article is to demonstrate the rupture between common sense and scientific knowledge of Chemistry from the epistemology of Gaston Bachelard. As a guideline for such an analysis, the concepts of immediate materialism and learned materialism, which appear mainly in the bachelardian work Le Matérialisme Rationnel of 1953, were taken as the great bases of thoughts that founded Chemistry science in different historical periods. It will be demonstrated that in Bachelard's epistemology the concept of immediate materialism equals the moment in which there was continuity between common sense and scientific knowledge and that the various ruptures and conceptual innovations that occurred in the present time will establish a new Chemistry based on a new basis of thought, entitled by Bachelard of learned materialism. Here, the materialism is in the advanced state of scientific culture, and by incorporating discursive knowledge about matter, it breaks with the knowledge of appearances and departs definitively from elementary ideas linked to common sense. The chemistry of the new scientific spirit is presented by bachelardian epistemology as an inventive science that creates its object, it instructs and orders reality from mathematical thinking through very peculiar techniques and thus distances itself from the immediate analysis of empirical data of ordinary reality. The Bachelard's epistemology chemistry points to a series of reorganizations and conceptual updates that serve to characterize the evidence of the evolution of scientific thought.
\end{abstract}

KEYWORDS: Bachelard; Materialism; Chemistry; Common sense; Rupture.

Introdução

Para demonstrar a questão da ruptura entre conhecimento comum e conhecimento científico na ciência Química através da epistemologia de Bachelard, propomos que seja necessário compreender os dois grandes momentos históricos que, segundo o autor, se apoiaram as investigações acerca dos fenômenos materiais. Estes dois momentos que nos referimos, são aqueles que Bachelard chamou em sua obra Le Matérialisme Rationnel (1953), de materialismo imediato e materialismo instruído.

As obras de Bachelard possuem um arcabouço conceitual bastante amplo. As expressões materialismo imediato, materialismo inato, 
materialismo inconsciente, materialismo ingênuo e materialismo prematuro são usadas por Bachelard para designar a mesma ideia. Igualmente, as expressões materialismo racional, materialismo instruído, materialismo discursivo, materialismo progressivo, materialismo fáctico, materialismo científico, materialismo ativo, materialismo trabalhado e materialismo ordenado são termos que entre si designam a mesma noção.

Estas noções são apresentadas no trabalho de Bachelard como duas bases que organizam o conhecimento, opiniões e práticas em épocas diferentes na história da Química. Sendo assim, o objetivo deste artigo é apontar a ruptura entre conhecimento comum e conhecimento científico na Química como uma questão intrínseca entre as duas bases materialistas supracitadas.

\section{O Materialismo Imediato}

O materialismo imediato é descrito por Bachelard como uma base de pensamento que se contenta com as experiências imediatas. Nas considerações do autor, tal base de pensamento não possuiu grande atividade técnico-experimental pelo fato de estar ligada à vida comum. Baseou suas ideias em metáforas, analogias e imagens. ${ }^{2}$ Trata-se também de uma mentalidade que não se desfaz das características sensíveis da matéria.

Bachelard fala que a imagem dos quatro elementos (terra, ar, água e fogo) foi forte nas explicações dos fenômenos da matéria sobre a base do materialismo imediato, por causa do valor que se atribuía aos dados sensíveis. É assim que a Alquimia e a pré-química são apresentadas como as duas formas prematuras de investigação da matéria, pelo fato mesmo de se apoiarem nas explicações elementares, valorizadas e sensíveis, que são características do conhecimento comum. Nesse tipo de conhecimento se tinha um uso abusivo de imagens e analogias de origem inconsciente. Também não se apresentava uma exigência racional compromissada com a objetividade, ou seja, a experiência era interpretada sem discursividade (BACHELARD, 1972a).

Bachelard em La Formation de L'esprit Scientifique ${ }^{3}$, afirma que o que existe de mais imediato na experiência primeira somos nós mesmo. Nesta obra, o autor traz o tema histórico da Alquimia para demonstrar o quanto as fantasias, os valores inconscientes e as bases afetivas e subjetivas podem obstaculizar a busca da objetividade científica. A Alquimia se tratava de uma cultura íntima criada pelo sujeito através de sua experiência psicológica que transportava para o conhecimento da Natureza seus desejos mais íntimos (BACHELARD, 1993). Observemos que é na experiência

${ }^{2}$ Na obra La Formation de l'Esprit Scientifique, Bachelard critica tais aspectos como causas de perturbação a todo conhecimento que busque a objetividade.

${ }^{3}$ Cap. II, “O primeiro obstáculo: A experiência primeira", seção VII. 
subjetiva que devem ser verificados os imediatismos do senso comum e as intuições ingênuas.

Em La Formation de L'esprit Scientifique Bachelard já apresenta a ideia contida em seu principal livro sobre filosofia da química, a saber, Le Matérialisme Rationnel (1953). A ideia é de que a Alquimia não prefigura a química científica existindo uma grande ruptura de pensamento. Para Bachelard, os químicos do século XIX erraram ao avaliarem a cultura alquímica sob um valor objetivo, porque não consideraram os aspectos psicológicos contidos na Alquimia (BACHELARD, 1993).

Conforme Bachelard, nenhuma explicação levou em consideração a oposição entre a Alquimia e a Química, mas pelo contrário, a leitura que se apresentou na história da Química revela uma visão continuísta e cumulativa do conhecimento, onde os historiadores tentaram mostrar que a química moderna teve como ponto de partida as investigações dos alquimistas.

A Alquimia através da perspectiva bachelardiana é apresentada como uma atividade que estava fundamentada no inconsciente humano, isto é, possuindo fontes muito profundas do psiquismo humano (BACHELARD, 1993). O simbolismo da Alquimia retratava condições psicológicas incontestáveis, pelo fato de não existir um método confiável de verificação. $\mathrm{Na}$ cultura alquímica, partia-se de “(...) conhecimentos subjetivos que não podiam ser submetidos a uma verificação e, caso o fossem, essa experimentação era muito mais uma comprovação interna do que externa." (BULCÃO, 1999, p. 129).

O simbolismo alquímico apresentou condições psicológicas fortes de resistências ao espírito científico experimental. "É contra essa estereotipia de origem afetiva e não perceptiva que o espírito científico deve agir". (BACHELARD, 1993, p. 60). É nesse sentido que Bachelard entende que a Alquimia não se trata de uma preparação para ciência química propriamente científica. O pensamento alquímico é colocado em termos de obstáculo. "A alquimia, repetimos, de modo algum prepara Química: ela a entrava." (BACHELARD, 1972a, p. 72).

$\mathrm{Na}$ experiência alquímica, perdia-se a capacidade de desenvolver conceitos objetivos que ajudariam no progresso referente à experiência real. Essas considerações mostram que a Alquimia se desviava de uma base materialista positiva e ativa, ao se vincular em intuições oriundas da vida íntima (BACHELARD, 1972a).

Bachelard, em sua análise acerca do materialismo imediato, ressalta que o modo de explicação pela intuição dos quatro elementos - terra, ar, água e fogo - possuía origem na subjetividade humana. A aplicação da doutrina dos quatro elementos, no passado como no presente, denunciam sua ingenuidade como formas de aplicações delirantes (BACHELARD, 1972a). 
As intuições a partir dos quatros elementos eram modelos de explicações ingênuas sobre a matéria, que se expandiam em cosmologias, cujas raízes de tais pensamentos fundavam-se no psiquismo humano. Por isso, Bachelard traz em Le Matérialisme Rationnel algumas noções de C. G. $\mathrm{Jung}^{4}$ para demostrar como a ideia de arquétipos inconscientes podem se exteriorizar no conhecimento e podem ser racionalizados se tornando entraves ao saber. Isso significa que a doutrina dos quatro elementos não podia se configurar como um racionalismo científico.

Conforme Bachelard, a pré-química dos quatro elementos se configurou como um falso racionalismo ao estabelecer como base explicativa o número quatro, que possuía origens em manifestações inconscientes. A pré-química valorizou as qualidades imediatas da matéria que consideravam os quatro elementos como bases de estudos para explicar os fenômenos.

A química dos quatro elementos abrangia três tipos diferentes de fenomenologia, a saber, uma fenomenologia do objeto, uma fenomenologia da matéria e uma fenomenologia cosmológica, porque os elementos eram considerados ao mesmo tempo matéria, objeto e princípio das coisas (BULCÃO, 1999).

No decurso de Le Matérialisme Rationnel é mostrado que a doutrina quaternária e seus símbolos se apresentam na história da Química como bem distinta em relação ao simbolismo da Química contemporânea. Bachelard (1972a), fala que a doutrina dos quatro elementos se caracterizou como um erro histórico e que foi eliminado sob a luz das retificações progressivas. A técnica experimental rompe com a doutrina quaternária e reforma a experiência imediata.

Ainda na base materialista imediata, a pré-química instituiu um racionalismo dos três elementos, onde se estabeleceram como princípios ativos a água, o fogo e ar e aplicou-se na experiência como meios de transformação da matéria. Essa doutrina dos três princípios, na pré-química, tentou explicar toda a dinâmica dos fenômenos materiais durante o século XVIII.

Em sua contextura histórica o materialismo imediato passa por várias rupturas que desvincula o conhecimento comum e imediato do saber científico. À guisa de exemplificação, Bachelard cita a descoberta através dos estudos de H. Cavendish de que a água não era um elemento e, paralelamente as descobertas acerca da natureza do ar com A. Lavoisier.

A consequência de tais descobertas é que a água deixou de ser compreendida como um elemento fundamental de explicação e passou-se à noção positiva de que ela é uma síntese dos gases. Enfatiza-se ainda que a própria noção de gás trata-se de um rompimento com o saber pré-científico,

${ }^{4}$ Em Le Matérialisme Rationnel, capítulo "Phénoménologie et matérialité" seção IX e também no capítulo "Le rationalisme arithmétique de la matière sous des formes prématurées”, seção III. 
onde o gás era associado à noção generalizada, valorizada e confusa de fluido, que era entendido como magnético, vital e podia dirigir tanto a vida como a morte (BACHELARD, 1972a).

Ainda a título de exemplificação, Bachelard mostra que a descoberta do oxigênio foi também uma revolução nas bases do materialismo imediato. Tal conquista trouxe para o conhecimento científico e filosófico muitas novidades que serviram como bases de preparação para o espírito científico, que necessitaria estar preparado para assumir novos pensamentos, acompanhar as revoluções, que são marcas do progresso da cultura humana (BACHELARD, 1972a).

Os exemplos supracitados na filosofia da química bachelardiana servem para apontar provas de reorganizações do pensamento, de rupturas na base do pensamento materialista imediato com a inserção do caráter experimental nas práticas científicas através da química positivista de J. Priestley e de A. Lavoisier.

A química positivista de A. Lavoisier pode ser colocada como um avanço ao se distanciar do conhecimento comum nos estudos científicos acerca dos gases. Entra-se na ciência moderna da matéria quando se demonstra que a respiração é uma combustão (BACHELARD, 1972a). Contudo, tais fatos não foram o bastante para estabelecer uma ruptura completa entre o conhecimento comum e o conhecimento científico na Química.

$\mathrm{Na}$ química positivista as investigações ainda se apoiavam em linhas substancialistas por meio de convicções imediatas e ingênuas da vida comum. O materialismo imediato ainda apresenta-se como fecundo, pois mesmo com a inserção da atividade experimental na ciência na época positivista, o conhecimento científico ainda estava ligado com senso comum.

Bachelard destaca em Le Rationalisme Appliqué que as diferentes espécies de $a r$ nos estudos de J. Priestley - o ar bom e o ar viciado -, não configuravam sequer um tipo de classificação racional na Química, haja vista que esta classificação apresentava falsos problemas. Priestley atribuiu juízos de valor, bom e mau, valores subjetivos que não poderiam alcançar conhecimentos objetivos. Os valores de bem e mal estiveram ligados como designações fundamentais do saber que desenvolveram ideias cosmológicas à qual se distanciavam do nível experimental (BACHELARD, 1977).

No Le Matérialisme Rationnel ${ }^{5}$ também são apresentadas características desse materialismo imediato, que resistiram como verdadeiros obstáculos a uma ciência que buscava ordenar os elementos químicos racionalmente. Os aspectos subjetivos e os valores inconscientes são muito enfatizados por Bachelard. Exemplo,

${ }^{5}$ Cap II, "Le paradoxe du matérialisme des philosophes. De la généralité à la spécificité. De l'homogénéité à la pureté", Seção III.

A ruptura na química entre o senso comum e o conhecimento científico a partir da análise de Gaston Bachelard David Velanes 
De fato, quando se olhava para sete o número de metais em correlação com os sete planetas, fortaleceu-se valores simbólicos inconscientes, adquiriu-se com muita facilidade o sistema das substâncias metálicas. Assim, ao longo tempo onde se professou a relação recíproca do sistema dos metais e do sistema planetário, não se pode conhecer a verdadeira síntese do espírito científico. (BACHELARD, 1972a, p. 106).

Bachelard refere-se a essa característica como uma inadequação de caráter imaginário sobre os números que não atribui ordem racional sobre as substâncias. A ordenação racional dos elementos se dará em um momento posterior da história da Química com os estudos de D. Mendeleiev. ${ }^{6}$ Outra característica referida é a adesão ao método da história natural no século XVIII. Foi assim que se tentou classificar os elementos em classes de famílias. Tais classificações operavam com um número muito pequeno de substâncias, pois estavam reduzidos por uma visão superficial sobre a Natureza.

A inserção de entes físicos na base da "química imediata" também se caracterizou como um obstáculo. Bachelard dá o exemplo da substancialização de alguns princípios como a luz, o calor e a eletricidade. Aqui, aparece de modo total o caráter do obstáculo substancialista ${ }^{7}$ que são próprias do saber comum e, a ciência positivista ainda se encontrava mesclada com esse tipo de saber. Foi nesse sentido que Lavoisier acreditou que a luz se tratava de uma substância que atuava sobre a matéria.

Tal visão se deve ao caráter sensível do conhecimento comum que via como prova as diferenças das qualidades que os corpos manifestavam, como por exemplo, a cor da matéria. Em outras palavras, a ideia era de que a luz atuava quimicamente na matéria. Isto correspondia a uma realidade que podia ser verificada pela experiência imediata e, tal pensamento, no decurso da Química, se apresentou pela fotoquímica primitiva.

De acordo com Bachelard, em Lumière et Substance (1934), a experiência fotoquímica primitiva não oferecia uma sistemática das observações qualitativas. Ela não oferecia nenhum modo de medição dos fenômenos. Era o percurso da química extensiva, da química nos moldes da

\footnotetext{
6 "Só na segunda metade do século XIX apresentou-se uma sistemática de elementos químicos numa perspectiva realmente instruída. A tabela de Mendeleev superou a era analítica de Lavoisier, fundando a química sincrética, isto é, aquela que não se fixa em uma determinada posição filosófica, mas, ao contrário, é aberta a todas elas. Essa sistemática dos elementos, que os mostrava como uma totalidade orgânica, fez desaparecer a contingência dos corpos simples, antes acumulados empiricamente." (BULCÃO, M. O Racionalismo da Ciência Contemporânea: uma análise da epistemologia de Gaston Bachelard. Londrina: Ed. UEL, 1999. p. 140-141).

${ }^{7} \mathrm{O}$ substancialismo era uma forma de pensamento que atribuía à substância valores ocultos e invisíveis. A noção de obstáculo substancialista está expressa na obra La Formation de L'esprit Scientifique (1938).
} 
epistemologia cartesiana, que se limitava a afirmar que as substâncias absorviam a luz (BACHELARD, 1970). Somente com a química positivista do século XIX que se incorporou na ciência da luz uma intuição materialista, que pode tratar os fenômenos luminosos de maneira mais experimental.

Por fim, outro aspecto do materialismo imediato que se apresentou na história da Química como um entrave a toda sistematicidade racional, refere-se às desigualdades entre os elementos encontrados na natureza. É possível perceber que essa característica está relacionada ao próprio método da história natural. Com efeito, alguns elementos são abundantes na natureza, como o ferro e o cálcio, enquanto outros são mais escassos, por isso a dificuldade de uma ordenação racional para se chegar a uma sistemática dos elementos (Bachelard, 1972a).

As concepções marcadas pelo materialismo imediato são denunciadas por Bachelard como "química imediata" ou "química das aparências" e ainda podemos dizer "química ingênua", apresentadas como distantes do que em sua epistemologia ele chamou de Química científica ou Química matemática. Foi preciso que esta ciência rompesse com o reino da experiência primeira, com o vínculo com a vida natural e comum e com todo imediatismo, para que alcançasse o materialismo instruído. Pode-se afirmar que é através desta noção que poderemos, por contraste, compreender de forma mais nítida a ruptura entre conhecimento comum e conhecimento científico na ciência Química.

\section{O Materialismo Instruído}

A ruptura com as teorias quaternárias põe o materialismo da Química no campo da diversidade dos objetos materiais. O primeiro passo para ordenar o pluralismo da matéria foi verificar a noção de homogeneidade material (BACHELARD 1972a). A ideia de homogeneidade das substâncias se apresentou nos estudos da matéria como um entrave ao progresso acerca do conhecimento dos fenômenos materiais, porque a noção de homogeneidade estava ligada à ideia de substancialização material.

Conforme Bachelard, cada época possui sua doutrina acerca das substâncias homogêneas. É a partir de tal noção que é possível fazer investigações sobre os fenômenos da matéria. Contudo, na base materialista imediata a noção de homogeneidade se encontrava altamente sensibilizada. Tratava-se de uma homogeneidade sensível. O novo materialismo da química rompeu com essa compreensão pelo fato de não trabalhar com a noção de "dado", estabelecendo uma relação indireta com a realidade empírica.

Na Química contemporânea a noção de homogeneidade é dirigida pela técnica. Trata-se, portanto de uma homogeneidade instruída e, sem tais 
métodos, é possível por em questão a validade objetiva da homogeneidade de uma substância. "Entramos, com a química, no reino das substâncias precisas, no reino das substâncias que a técnica marca precisamente, dandolhes uma total homogeneidade." (BACHELARD, 1972a, p. 80).

Talvez, o fato mais importante apresentado por Bachelard como ruptura é a busca de uma sistemática química, uma vez que ao instituir uma sistemática dos elementos, a Química contemporânea rompe com as organizações prematuras que partia dos dados sensíveis da matéria.

A tabela de D. Mendeleiev foi organizada racionalmente e distanciada dos aspectos imediatos, dos objetos empíricos do conhecimento comum. Com Mendeleiev se deu a formulação das primeiras leis acerca da periodicidade dos elementos químicos. Ressalta Bachelard, em Le Pluralisme Cohérent de la Chimie Moderne (1932), que com a tabela de Mendeleiev uma nova era começa para a Química geral. "Mendeleev entreveis uma doutrina geral das qualidades particulares e preparou a harmonia das substâncias." (BACHELARD, 2009a, p. 10).

O quadro de Mendeleiev deu uma totalidade na organização dos corpos simples que antes eram indeterminados e classificou os elementos linearmente em grandes famílias. O que está posto no quadro mendeleviano é a ordenação dos corpos simples em famílias de elementos a partir do peso atômico em uma linha horizontal e das valências químicas ordenadas por uma linha vertical. O peso atômico pode ser considerado de forma geral como o peso absoluto de um átomo. Este conceito sofreu grandes mudanças na história.

Conforme Bachelard, com Mendeleiev surge uma revolução de ideias. A Química entra em sua era sincrética e se afasta da era analítica lavoiseriana. Aqui, é possível apontar outro ponto de ruptura entre conhecimento comum e conhecimento científico, uma vez que a matéria era antes ordenada através de suas qualidades sensíveis, da realidade imediata e cercada por uma filosofia da natureza. Esta espécie de realismo se rompeu quando se buscou entender as formas intimas da matéria. Tal fato reorganizou o pensamento ao afastar a realidade natural como meio para alcançar a sistemática dos elementos.

No trabalho de Bachelard, é com a noção de número atômico que parece haver um desprendimento total entre conhecimento científico e conhecimento comum. A noção de número atômico ultrapassa a ideia de peso atômico ao configurar um campo de estudo totalmente novo sobre a matéria. Tal conceito é de acordo com Bachelard uma ideia nova que pode ser considerada como uma das grandes conquistas técnicas da ciência contemporânea. Isso quer dizer que não existe uma continuidade da noção de peso absoluto do átomo.

O número atômico pode ser descrito como o número de ordem de um elemento químico no quadro de Mendeleiev. Tal número se tornou um valor teórico e explicativo sobre uma base matematizada (BACHELARD, 
2009a). É assim que, de modo revolucionário, o número atômico designa como princípio ordenador a quantidade de elétrons que existem em um determinado átomo na tabela mendeleviana (BACHELARD, 1972a).

Uma nova sistemática então se institui na Química através da noção de número atômico. Um corpúsculo como o elétron exige novas determinações por não ser um "dado" natural e notável. De acordo com Bachelard, este caráter da sistemática eletrônica na Química se tratou de um campo novo de racionalidade que informa profundamente a realidade empírica de modo indireto através de técnicas específicas.

Foi possível falar de um "racionalismo aritmético da matéria" quando o quadro de Mendeleiev foi atualizado pelos novos conceitos. Estabeleceu-se uma ruptura acerca do conceito de matéria, que passou a ser pensada pela quantidade de elétrons de um átomo. A matéria se tornou eletrônica aritmeticamente e perdeu seu caráter substancial (BACHELARD, 1972a). E Bachelard explica:

(...) podemos mostrar uma diferença filosófica fundamental entre os períodos da tabela de Mendeleev primitiva, fundada sobre as qualidades químicas e o período da tabela moderna fundada sobre as estruturas eletrônicas. Os períodos primitivos, tal como aparecem nas investigações empíricas são dos fatos sem explicações. (...) Mas quando a valência química é explicada por organizações eletrônicas, o empirismo aparece como um conhecimento de primeira posição, conhecimento que constata mais não explica. A teoria eletrônica tem então a função de uma ordem de razões que explicam os fatos. (BACHELARD, 1972a, p. 117).

A sistemática eletrônica se tornou a base da ordenação da tábua de Mendeleiev. Em consequência, novos tipos de estudos acerca dos fenômenos da matéria são introduzidos na Química, por exemplo, a influência da mecânica quântica.

No pensamento bachelardiano, a Química quântica demarcou definitivamente uma ruptura com o materialismo imediato, porque fez aparecer um novo corpo de racionalidade, um novo campo de aplicação nos estudos químicos. Tratou-se de um momento revolucionário na história da Química que impôs uma verdadeira descontinuidade com o imediatismo da pré-química e da química positivista.

A Química quântica se desfez da doutrina materialista imediata e reforçou os fundamentos de uma ciência construtiva fundamentada na matemática (BACHELARD, 1972a). Uma inovação que reforça a tese da ruptura entre conhecimento comum e conhecimento científico é a potência do cálculo na atividade racionalista científica contemporânea. "Para estabelecer os diagramas que fixam nossos conhecimentos sobre as densidades eletrônicas ao redor dos núcleos (...) nos vemos levados a 
calcular os términos de uma larga série tripla de Fourier." (BACHELARD, 1972a, p. 272).

Aponta Bachelard, que o cálculo dos diagramas se trata de atividades científicas que transcende a toda capacidade humana e são efetuadas por instrumentações científicas muito sofisticadas. Isto quer dizer que a inserção do cálculo revolucionou formas de racionalidades e determinou reorganizações no pensamento. Bachelard nos chama à atenção para o refinamento e modificações da técnica na ciência contemporânea, que não podem ser compreendidas como as técnicas mecânicas do conhecimento comum. Elas não possuem continuidades entre si. As técnicas da atividade científica contemporânea mesclam representação e experimentação.

Com a Química quântica a energia é quantificada através do princípio de exclusão de Pauli, onde se atribui números quânticos aos elétrons para deduzir sua localização no interior átomo. Nesse sentido, pode-se dizer que a Química se matematiza e se institui como uma ciência dessubstancializada e desmaterializada. Com efeito, se perde o sentido realista do elemento, afirma (BULCÃO, 1999). Ainda segundo a autora, dessubstancialização da Química se tornou mais forte quando a quantificação adquiriu apenas relações de probabilidade.

Bachelard dá o exemplo da quadrivalência do átomo de carbono. ${ }^{8} \mathrm{~A}$ Química quântica modificou a visão das valências tetraédricas por uma mudança na concepção de estrutura. Bulcão (1999) esclarece que com a ciência química quantificada, a noção de estrutura de uma substância perdeu seu sentido realista e substancial. Estabeleceu-se uma nova visão de que a substância possui uma multiestrutura. Em outras palavras, a nova Química trabalha com uma diversidade de estruturas que designam uma mesma substância. A substância é possuidora de vários estados estruturais, onde é possível inferir que a noção de estrutura exige uma atualização conceitual.

Para Bachelard, uma estrutura não pode ser pensada e nem explicada de maneira comum, uma vez que no materialismo instruído tal noção se apresenta em sentido abstrato. É assim que a estrutura tetraédrica do átomo de carbono não pode ser pensada geometricamente situada na realidade comum. A estrutura tetraédrica do átomo de carbono tem a função de instruir as associações deste átomo com outros elementos.

(...) a atividade estruturante da matéria, uma atividade que consiste em preencher bem o espaço de acordo com condições suplementares cada vez mais numerosas e mais delicadas. (...) é doravante demasiado brutal dizer que o átomo de carbono é tetraédrico. Só tem grandes possibilidades de tetraedrização. No átomo, tudo é função, tudo é possibilidade. Quando o átomo é solicitado por outros átomos para formar moléculas,

\footnotetext{
${ }^{8}$ Em Le Materialisme Rationnel, Capítulo IV, "Le Matérialisme Composé”.
} 
ele se exibe de algum modo, tetraédricamente. (BACHELARD, 1972a, p. 229).

De acordo com Bachelard, na Química clássica as valências se apresentavam apenas como postulados, isto é, emitiam-se hipóteses que se mostravam como simples realizações do princípio de razão suficiente para tornar possíveis as explicações das valências. "Pelo contrário, estamos de acordo com o exemplo da mecânica quântica na Química ante uma promoção filosófica no sentido de necessidade." (BACHELARD, 1972a, p. 226).

O que Bachelard apresenta aqui em jogo é a necessidade do cálculo, a sujeição dos cálculos sobre um método geral do conhecimento racional, que faz o saber entrar no âmbito de valores de necessidade não mais guiado pelo princípio de razão suficiente, mas pelo princípio de razão necessária na organização racional dos elementos. Então, a ideia de necessidade ultrapassa com a matemática todo aspecto hipotético. A Química contemporânea vai se basear no cálculo para fundamentar os estudos científicos.

\section{O caráter inventivo do materialismo instruído como ruptura total com o senso comum}

O materialismo instruído é apresentado como uma base de pensamento complexa que caracteriza especificamente a Química contemporânea. Trata-se de um materialismo complexo por trabalhar com uma diversidade e pluralidade de objetos materiais. É um materialismo que experimenta, progride, trabalha, cria e instrui os fenômenos humanamente (BACHELARD, 1972a). Tal tipo de atividade de pensamento surge após o fracasso das formas racionalistas prematuras e da química positivista sobre os estudos da matéria. É assim que, por exemplo, uma “(...) combinação intra-atômica apresenta em relação à combinação química comum uma verdadeira ruptura de escala. Pode haver ruptura de método e até de princípio". (BACHELARD, 1986, p. 60).

Bachelard apresenta o materialismo instruído como o verdadeiro materialismo da Química contemporânea ao exigir o modelo matemático como princípio da experiência. Isso quer dizer que o materialismo assume um racionalismo ativo como doutrina científica, onde é possível agora falar de uma Química matemática no mesmo sentido de uma Física matemática (BACHELARD, 1972a). Na Química matemática, o modelo matemático fundamenta e ordena uma sistemática dos elementos químicos. "A matemática moderna é, de fato, tanto a ciência da ordem quanto a ciência do número." (BACHELARD, 2009a, p. 11).

A Química matemática tem sua base fundamentada na ordenação racional das qualidades dos elementos. Isso que dizer que a matematização da Química instituiu uma desmaterialização na noção de matéria, uma vez 
que a Química ao se afastar do realismo imediato pôde modificar o conceito de substância. A matéria passa a ser pensada como energia.

No novo espírito científico, a matéria adquire uma nova noção. A Química contemporânea apresenta o conceito de matéria como energia e que possui uma objetividade científica complexa ao romper com a própria noção de energia do conhecimento comum. Ou seja, não se trata mais de um materialismo que considera a matéria como algo inerte e desprovida de energia interna. Isso quer dizer que a energia se tornou base dos estudos científicos.

O fenômeno químico é manifesto por energia e deixa de ser simples aparência e descrição. Torna-se necessário conhecer as relações energéticas dos fenômenos químicos quando se busca a elaboração de novas substâncias. Portanto, os fenômenos da matéria pelos estudos químicos contemporâneos devem ser explicados pelas leis da energia, onde se pode falar que se tratam de investigações extremamente profundas. ${ }^{9}$

Essas considerações mostram que o materialismo instruído não é de acordo com Bachelard uma filosofia especulativa. Trata-se de um pensamento que age na matéria como marca do novo racionalismo científico. Bachelard fala de um pensamento atuante e criador, que não mais se envolve com as noções da subjetividade humana, mas um pensamento que se aplica e organiza novos corpos. A química contemporânea administra forças reais na linha da verificação objetiva (BACHELARD, 1972a).

Desta forma, o materialismo da nova Química surge como uma mentalidade criativa que exerce poder sobre a matéria em que os fenômenos materiais são eles mesmos construídos humanamente. Em La Philosophie du Non ${ }^{10}$, Bachelard explica que a química contemporânea desenvolve fórmulas que agem como substitutos teórico-racionais. Nesse sentido, a

9 Nas palavras de Bulcão (1999), “o pensamento contemporâneo inaugura uma nova perspectiva de abordagem da matéria. Até então a matéria era tida como algo inerte, limitado e estável, pois a ciência, continuando o conhecimento comum, partia de pressupostos fundamentados na observação imediata. Bachelard, procura em suas obras ressaltar a ruptura entre ciência e conhecimento comum, que vai ser umas das características de nossa época. Na Química, essa ruptura implica um abandono das idéias realistas que dominavam o estudo da matéria até o século XX e que impediram o desenvolvimento de conhecimentos objetivos e a proliferação de novas técnicas. Entrando no domínio da Química contemporânea, onde prevalece o novo espírito científico, vamos verificar que não se trabalha aí com intuições comuns, provenientes do conhecimento imediato, e que a noção de matéria fundamental nesta ciência, sofreu uma dessubstancialização. A Química de hoje abandonou o realismo, passando ao plano da matemática probabilitária. Pra se compreender como a Química deixou de ser realista, modificando o sentido do conceito de substância, Bachelard explica a organização energética da matéria." (BULCÃO, Marly. $O$ Racionalismo da Ciência Contemporânea: uma análise da epistemologia de Gaston Bachelard. Londrina: Ed. UEL, 1999, p. 131-132).

${ }^{10}$ Cap III. "Le Non-Substantialisme. Les Prodromes D’une Chimie Non-Lavoisienne", seção III. 
fórmula é anterior à experiência que adquire possibilidades claras de realização pela técnica. Isso quer dizer que as experiências químicas contemporâneas são pensadas antes da experimentação através de uma teoria elaborada (BACHELARD, 1996).

O pensamento teórico-matemático é anterior ao fenômeno. Bachelard oferece o exemplo do corpo colorido que é antes construído pela elaboração teórica instruída matematicamente. Isso significa que não se trata de descobertas sobre fenômenos do mundo natural, mas de construção de fenômenos por aparelhos peculiares. A atividade da química contemporânea é criar uma lei que possa constituir uma nova substância. Estar-se-á, de agora em diante, sobre a substituição da observação de objetos notáveis por uma elaboração racional que constrói o objeto artificial.

A atividade experimental está ligada a uma técnica que elimina a irracionalidade da substância. Assim, pelo ordenamento racional das substâncias é possível alcançar a pureza das mesmas. Estabelecem-se critérios que garantem, junto à técnica, a pureza das substâncias. Conforme Bachelard, só é possível falar de uma Química bem fundada quando se conhece suficientemente os elementos químicos em relação à pureza. Para tanto, é preciso de critérios racionais bem elaborados que estabeleçam uma ordenação segura acerca dos elementos da matéria.

As novas técnicas de purificação são apresentadas por Bachelard como um marco do materialismo racionalista, que tem estatuto objetivo garantido pela comunidade científica. Trata-se de técnicas inovadoras diferentes das técnicas positivistas onde se bastava a balança para determinar os pesos atômicos. $\mathrm{O}$ uso sistemático da balança configura apenas o começo da ciência química (BACHELARD, 2016). Por sua vez, no novo espírito científico, pesam-se isótopos por uma técnica indireta e nova. A balança é então substituída pelo espectroscópio de massa que se baseia na ação dos campos magnéticos e elétricos. Diferentemente da balança de Lavoisier, o espectroscópio de massa pode ser entendido como um instrumento indireto, porque se afasta da experiência imediata e usual (BACHELARD, 1977).

O elevado grau de refinamento técnico possibilita estabelecer graus de pureza que é ordenada racionalmente através de reativos específicos. Com efeito, tem-se uma pureza construída pela atividade humana e não pela Natureza. "A pureza de uma substância é, pois, uma obra humana. Não pode ser tomada por um dado natural." (BACHELARD, 1972a, p. 139).

A nova Química trabalha com uma artificialidade que se afasta dos dados empíricos da realidade natural. Destarte, os procedimentos de purificação contemporâneos rompem com a ideia de uma pureza absoluta e estabelece uma relatividade da substância purificada, onde é possível falar de diferentes graus de pureza.

Diz Bachelard (1972a), que a substância é dada pela Natureza, porém não está purificada. Ela será pura após o trabalho técnico de 
purificação que exige uma racionalidade específica. Em consequência, o valor de pureza não se encontra pelo natural, mas na aplicação da técnica que apresentará outro tipo de substancialismo onde é possível falar de uma substância sem acidente ${ }^{11}$.

O papel da técnica é importante para a compreensão da ruptura entre o materialismo instruído e o materialismo imediato. As técnicas da Química contemporânea afastam as convicções imediatas do conhecimento comum, elaboram experiências bem precisas e bem estabelecidas, capazes de transformar as propriedades da matéria. Então, as relações da Química científica não se apresentam na Natureza, porque se trata de uma ciência caracterizada pelo espírito de construção, isto é, como uma ciência que cria uma natureza segunda ao se afastar da realidade imediata.

O objeto químico da nova Química é abstrato-concreto, ou seja, é um objeto do conhecimento comum, mas uma espécie de "objeto segundo", criado pela atividade humana. Pode-se afirmar que o materialismo instruído fundamenta uma "ciência do futuro", porque sua racionalidade é produtora das descobertas.

A Química contemporânea ao trabalhar com a atividade da transmutação do núcleo dos elementos instituiu outra ruptura em sua história. O problema do núcleo das substâncias se apresenta como uma atividade de criação, isto é, de criar núcleos não existentes na natureza. Por exemplo, o elemento neptúnio ( $\mathrm{Np}$ ) não é um elemento existente na Natureza. Ele é um elemento artificial, sintético, isto é, criado racionalmente por uma técnica bem específica seguindo a atividade da transmutação nuclear (BACHELARD, 1972a).

A Química contemporânea é uma ciência da transformação e criação material. A atividade criadora é, por sua vez, o caráter fundamental do materialismo instruído, que não pode ser pensado dissociado dos instrumentos técnicos - do materialismo técnico. A nova Química contemporânea quando vai à Natureza é sempre depois dos estudos técnicos que ocorre nos laboratórios (BACHELARD, 1972a).

\section{Considerações finais}

Para Bachelard, é na linha da ciência construtiva que se deve pensar o começo do materialismo instruído significativamente distanciado do

\footnotetext{
${ }^{11}$ Uma substância sem acidente é o produto de um trabalho técnico-racional, construída na cidade científica - cité scientifique. São substâncias altamente controladas que suprimem qualquer flutuação das qualidades. É uma substância ordenada racionalmente que possui identidade absoluta. “(...) o materialismo ativo tem precisamente por função submeter tudo o que possa ser qualificado de irracional em suas matérias, em seus objetos. A Química, confiante em seus a priori racionais, entrega-nos substâncias sem acidentes; depura todas as matérias da irracionalidade das origens.” (BACHELARD, G. O Racionalismo Aplicado. Rio de Janeiro: Zahar, 1977, p. 13-14).
} 
conhecimento comum e sensível. Aqui, o materialismo se encontra no estado avançado da cultura científica e, ao incorporar o conhecimento discursivo sobre a matéria, rompe com os conhecimentos das aparências e distancia-se definitivamente das ideias prematuras dos quatro elementos. Ele rompe com senso comum. Trata-se de um racionalismo da Química que trabalha contra os imediatismos e busca a existência de novas experiências ao rechaçar as experiências primeiras, as intuições imediatas. O materialismo racionalista ao se estabelecer por completo rompe de maneira brusca com o materialismo imediato. Através de sua atividade racionalista, retifica constantemente o real. Cria-se um real retificado e trabalhado como próprio da ação humana.

Ao olhar o passado das ciências, podem-se perceber as inúmeras reorganizações do pensamento. É assim que, diante das novas teorias e técnicas de extrema precisão, a Química contemporânea tem o poder de julgar seu passado histórico a partir da consciência de seus erros. A partir da questão da ruptura epistemológica no pensamento de Bachelard, deve-se dizer que entre as doutrinas alquimistas e as teorias nucleares não existe nenhuma ligação. Não se vai da Alquimia até a Química positivista e nem desta para a Química matemática.

A ruptura entre conhecimento comum e conhecimento científico na Química deve ser analisada a partir das duas formas de materialismos, como bases subjacentes ao pensamento científico de épocas diferentes e que é possível de ser analisado através do olhar histórico acerca da evolução das ciências. A Química se desprendeu da realidade comum estabelecendo uma relação com o mundo empírico somente de modo indireto. Pela análise de Bachelard, é possível afirmar ainda mais, a saber, de que a Química ao revolucionar seus conhecimentos, se tornou uma ciência construtiva, que induz a realidade a partir do pensamento matemático através de técnicas muito peculiares. 


\section{Referências bibliográficas}

BACHELARD, Gaston. La Formation de l'Esprit Scientifique. Paris: J. Vrin, 1993.

. Essai sur la Connaissance Approchée. Paris: J. Vrin, 1986.

Le Nouvel Esprit Scientifique. Paris: PUF, 1999.

"Lumière et Substance". In: Études. Paris: J. Vrin, 1970.

O Racionalismo Aplicado. Rio de Janeiro: Zahar Editores, 1977.

Le Matérialisme Rationnel. Paris: PUF, 1972a.

. La Philosophie du Non. Paris: PUF, 1996.

. O Pluralismo Coerente da Química Moderna. Rio de Janeiro:

Contraponto, 2009a.

. L'Engagement Rationaliste. Paris: PUF, $1972 \mathrm{~b}$.

BARBOSA, Elyana. Gaston Bachelard: O Arauto da Pós-Modernidade. Salvador: EDUFBA, 1996.

BULCÃO, Marly. O Racionalismo da Ciência Contemporânea: uma análise da epistemologia de Gaston Bachelard. Londrina: UEL, 1999.

Autor(a) para correspondência: David Velanes, Universidade Federal de Minas Gerais, Faculdade de Filosofia e Ciências Humanas, Avenida Antônio Carlos, 6627, Pampulha, CEP 31270-901, Belo Horizonte - MG, Brasil. dvelanes@gmail.com 